\title{
Expert opinion: diagnosis and treatment of proximal hamstring tendinopathy
}

\author{
Lasse Lempainen ${ }^{1}$ \\ Kristian Johansson ${ }^{2}$ \\ Ingo J. Banke 3 \\ Juha Ranne ${ }^{1}$ \\ Keijo Mäkelä4 \\ Janne Sarimo ${ }^{1}$ \\ Pekka Niemi ${ }^{1}$ \\ Sakari Orava ${ }^{1}$
}

1 Department of Orthopaedics, Hospital NEO, Turku, Finland

2 Department of Surgery, Satakunta Central Hospital, Pori, Finland

3 Clinic of Orthopedics and Sports Orthopedics, Klinikum Rechts Der Isar, Technische Universität München, Munich, Germany

4 Department of Orthopaedic Surgery and Traumatology, University of Turku, Turku, Finland

Corresponding author:

Lasse Lempainen

Department of Orthopaedics, Hospital NEO

Joukahaisenkatu 6

20520, Turku, Finland

E-mail: lasse.lempainen@sairaalaneo.fi

\section{Summary}

Background: proximal hamstring tendinopathy (PHT) is a disabilitating disease often causing underperformance in the athletically demanding patients. The main symptom of PHT is lower gluteal pain especially during running or while prolonged sitting. Mainly affecting athletically active individuals, PHT is a considerable challenge for treating health care professionals.

Purpose: this paper aims to concisely present the literature on PHT to guide health care professionals treating these patients and doing research on the subject.

Methods: we reviewed the literature on $\mathrm{PHT}$ through literature search of scientific journal databases.

Conclusions: as a tendinopathic pathology, it is a rather recently discovered exertion injury. As with other chronic tendon overuse injuries, current treatment strategies are unspecific with uncertain outcomes due to the unknown etiology of the ten- don degeneration. Diagnostic features as well as both operative and non-operative treatments are evaluated from a clinical perspective, providing up to date information for clinicians and sports medicine therapists dealing with hamstring problems. Level of evidence: $V$.

KEY WORDS: exertion injury, hamstring, tendinopathy, treatment.

\section{Introduction}

Problems related to hamstring muscles and tendons range from benign hamstring strain injuries to severe total 3-tendon ruptures ${ }^{1}$. Acute hamstring injuries are well documented in literature but chronic pains and problems are not as well known. In this expert opinion paper, we reviewed the literature on proximal hamstring tendinopathy (PHT) through literature search of scientific journal databases. Despite different anatomy there are similarities to tendinopathies of other tendons in regards of chronicity, disabilitation and histology. In other tendons the clinical presentation of painful swelling impairing performance is defined as tendinopathy and more specific diagnoses such as tendinosis are specified after surgery and histological investigation ${ }^{2}$. PHT should be regarded similarly, a clinical diagnosis which can be specified through operative and histological investigation. Diagnostic features as well as both operative and non-operative treatments are evaluated from a clinical perspective, providing up to date information for clinicians and sports medicine therapists dealing with hamstring problems. This article submits to the ethical standards of the journal ${ }^{3}$.

\section{Pathogenesis and predisposition factors}

What we know about the pathology of PHT is limited to few studies. Histopathological samples from proximal hamstring tendons have shown rounding of fibrocyte cell nuclei, increased amount of extracellular matrix, disruption of normal collagen structure and neovascularisation including observations of fatty degeneration ${ }^{4}$. The microscopical histology is the same as the histology that defines tendinosis in other weight bearing tendons such as the Achilles and patellar tendons ${ }^{5,6}$. Currently many endogenous mediators induced by thermal, mechanical, vascular or neuronal stimuli are investigated in the pursuit of the 
pathomechanisms in both tendon degeneration and pain. These include neuropeptides, matrix metalloproteinases, inflammatory cytokines and heat shock proteins $^{7-9}$. Of the novel genetic risk factors that have been discovered, the most notable is in the polymorphisms of the COL5A1 gene that involves the production of collagen type $\mathrm{V}^{10}$. Repetitive stress seems to correlate strongly with the development of PHT, as only a few non-athletes have been reported in the literature $^{4,11}$. However, by experience of the authors and Saikku et al., a non-athletic group of patients that are generally mid-aged is also recognized, usually with predisposing occupational strains by squatting, bending over or other functions involving repetitive hip flexion ${ }^{12}$.

In general, the prevalence of tendinopathy seems to increase with age, but patients treated surgically for PHT are often relatively young, physically active individuals ${ }^{4,13}$. A distinction between cumulative physical stress and age related degeneration of tendons is not established. It was, however demonstrated in a study by Ruzzini et al., that tendon stem cells isolated from older hamstring tendons had weaker potential in regards of clonogenicity, adipose and osteogenic inductability but better chondroid inductability, suggesting a possible biological basis for age-related differences ${ }^{14}$. The remaining knowledge about the etiology of PHT is that of patellar and Achilles tendinopathy given that tissue metabolism is comparable. Additionally, non-weight bearing tendons that feature the same pathologic histology in chronic pain syndromes are those of the rotator cuff, as well as the tendons in medial and lateral epicondylitis ${ }^{15}$. Several extrinsic and intrinsic risk factors for chronic tendinopathy have been proposed, frequently based on a paper by Kannus ${ }^{16}$. Because sports activities appear similar in both PHT and other tendinopathies, some of these could certainly be adopted for PHT, but there is weak, if any, science to back these risk factors ${ }^{4,17,18}$. Based on the reports on PHT, men are predominantly affected, main sports include track and field events and soccer and physically active patients are aged under their $40 \mathrm{~s}^{4,11,19-24}$.

\section{Clinical presentation}

A thorough history and examination play a key role in the diagnosis of PHT. The main symptom of PHT is pain in the lower gluteal region, sometimes radiating along the hamstrings to the posterior thigh ${ }^{4,25}$. The pain mainly manifests during running at a faster pace or while sitting for a prolonged time. Typically, the pain appears without any sudden trauma and gradually becomes worse. However, sometimes patients also report history of repetitive hamstring injuries. In general, continued training and stretching of the hamstrings make the situation gradually worse.

On clinical examination, there is often palpable tenderness and pain over the ischial tuberosity against resisted knee flexion. Furthermore, active stretching of the hamstrings recreates the pain at the site of the ischial tuberosity as well. Typically, peripheral neurological tests and ENMG studies are normal and no strength deficiencies are noted in knee flexion or in hip extension.

\section{Imaging}

The objective of imaging is to confirm the presence of hamstring tendon pathology and to assess the extent of the injury. The imaging tests can help to identify which patients may benefit from surgical treatment, and they also may provide estimations for the probable length of the recovery ${ }^{26}$. Magnetic resonance imaging (MRI) and ultrasonography (US) are the methods of choice for the visualization of the hamstring tendon complex ${ }^{27}$. Familiarity with the normal anatomy is the key in recognizing tendon abnormalities with both imaging modalities. Ultrasound is a readily available and cost-effective imaging technique that allows dynamic evaluation for hamstring tendons with resolution that might equal or even surpass MRI, but its usefulness depends of the experience of the operator.

The advantage of MRI is better soft tissue contrast. It is more sensitive than US in detecting tendinopathy and peritendinous edema of the proximal hamstring tendons ${ }^{23}$. MRI is more likely to be beneficial in those patients whose US examinations are abnormal. The findings of PHT on MR images are: increased signal intensity on T1- and T2-weighted images, thickening of the tendons, peritendinous edema and bone marrow edema like changes in the ischial tuberosity. However, a recent study showed that signal changes on T1- and T2-weighted images are a common finding in asymptomatic patients ${ }^{28}$. Peritendinous edema with a distal feathery pattern is more reliable sign of tendinopathy. Changes that mimic bone marrow edema and thickening of tendons are also more often seen in symptomatic than asymptomatic patients. However, all these changes can also be seen in asymptomatic tendons, and therefore, a close correlation between imaging and the clinical findings is paramount. Typical MRI findings of PHT can be seen in Figures $1 \mathrm{~A}-\mathrm{C}$.

\section{Conservative treatment}

A common consensus on the best conservative management of PHT is still lacking due to the low scientific evidence on effectiveness with interventions being used. However according to the conceptual model of inter-relationship between the multiple factors involved in hamstring pathology a multimodal approach is favorable ${ }^{1,29}$. Notably for PHT only little clinical literature regarding best conservative management other than general tendinopathy recommendations exist. Due to special anatomical features of the proximal hamstring complex such as deep localization with often thick soft tissue coverage as well as sciatic nerve's close relation, general recommendations for treatment of tendinopathy have to be questioned in terms of effectiveness and safety on a scientific base before being transferred to PHT. 

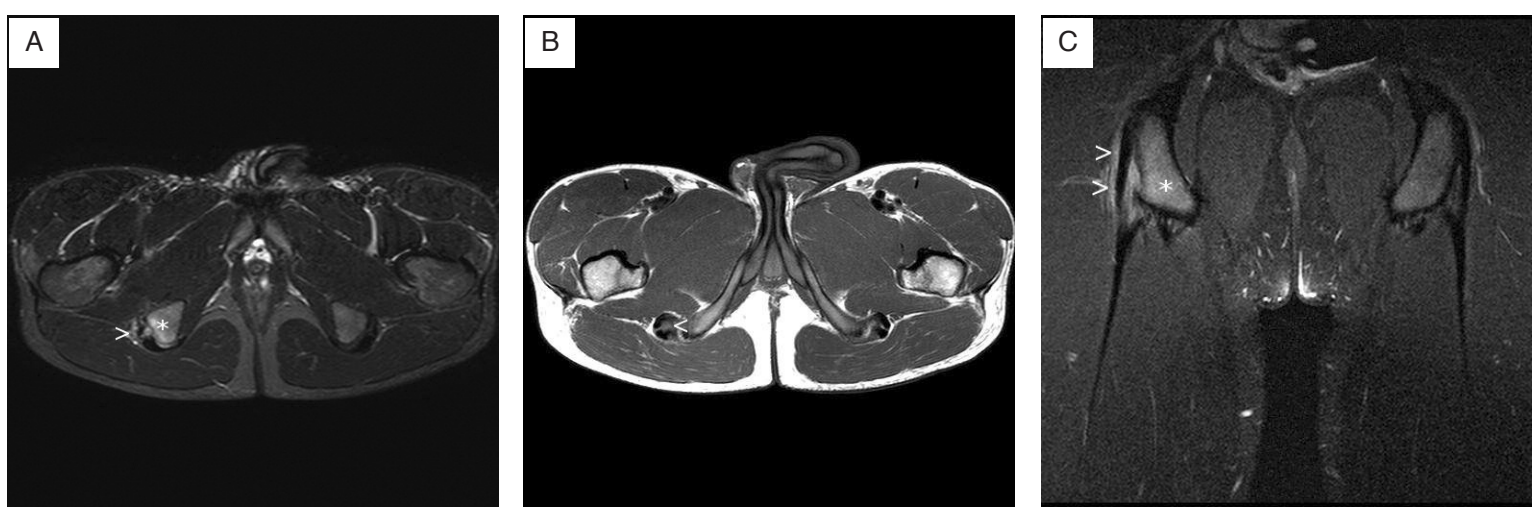

Figure $1 \mathrm{~A}-\mathrm{C}$. MR images of a 24-year-old long-distance runner with the chronic PHT on the right side. (A) Axial STIR image ( $\mathrm{TR}=3080 \mathrm{~ms}, \mathrm{TE}=60 \mathrm{~ms}$ ) shows peritendinous edema (arrow head) and bone marrow edema-like changes (asterisk). (B) Axial T1-weighted FSE image (TR=525ms, TE=20ms) shows intratendinous signal changes and thickening of the hamstring tendons (arrow head). (C) Coronal T2-weighted fat suppressed FSE image (TR=3675ms, TE=40ms) shows peritendinous (arrow heads) and bone marrow edema-like changes (asterisk).

Traditional treatment methods for PHT are by the majority comparable to those of other tendinopathies: they include relative rest and ice for symptoms relief in the initial phase, reduction or pause of sports activity, nonsteroidal anti-inflammatory drugs (NSAIDs), soft tissue mobilization, physiotherapy and continuous home exercise program focusing on progressive eccentric hamstring strengthening and core stabilization ${ }^{30}$. The time to full recovery is normally between 1-3 months. In uncomplicated cases mostly good results have been demonstrated with full return to pre-injury sports level and great subjective outcomes, however minimal pain or discomfort may persist a few weeks longer ${ }^{25}$.

Eccentric exercise programs with musculotendinous junction strengthening and promotion of intratendinous collagen fiber cross-linkage to enable remodeling and flexibility improvement have demonstrated their potential in treating tendinopathy ${ }^{24,31,32}$. Several additional physical therapies have been described in the treatment of PHT including soft tissue mobilization, lumbopelvic stabilization exercises, trigger point dry needling and electrical muscle stimulation combined with US $24,33,34$.

Proprioceptive training was shown to be beneficial for neuromuscular control as summarized by White ${ }^{24}$. Tendon stem cells are suspected to play a major pathogenic role also in $\mathrm{PHT}^{35}$. Low mechanical stretching has been shown to promote stem cell differentiation in tenocytes to possibly maintain tendon homeostasis ${ }^{35}$. In contrast large mechanical load stretching may have adverse effects, causing tendon degeneration in form of tissue calcification, lipid accumulation and mucoid formation through unfavorable stem cell differentiation into non-tenocyte osteogenic, lipogenic and chondrogenic lineages ${ }^{35}$. According to our experience stretching of hamstrings complex often worsens the pain in $\mathrm{PHT}^{30}$. However in up to $20 \%$ of patients symptoms can endure $>6$ months with failing response to conservative treatment ${ }^{36,37}$. Predominantly as option for recalcitrant disease refractory to conventional treatment novel therapeutic approaches are recognized including shockwave (SWT) and ultrasound (US) therapy, ultrasound-guided corticosteroid injection and Platelet rich plasma (PRP) injection 19,23-25,38,39. When compared to a combined NSAID, physiotherapy and a hamstring specific exercise program, SWT had significantly better results with a mean follow-up of 10.7 months $^{19}$.

US-guided corticosteroid injection of the tendon sheath is used by some authors in $\mathrm{PHT}^{25}$. However detrimental effects as slowed long-term tissue healing caused by inhibition of collagen linkage, incomplete healing and recurrent injury have been reported $40-42$. Additionally symptoms often recur after initial good short-term results ${ }^{30}$. In two reports with peritendinous administration of corticosteroids in PHT no complications were reported, with symptom resolution for $39 \%$ of the patients at a mean follow-up of 24.8 months in the other study and symptom relief for $24 \%$ of the patients at 6 months, in the other 23,43 .

PRP as a novel biological approach has been highlighted on a limited evidence to have therapeutic potential for several tendinopathies and operative (musculo)tendinous reconstructions. However robust clinical trials are needed to prove efficacy and safety ${ }^{44,45}$. Two studies have described the use of PRP in PHT with beneficial effects, however lacking in method quality and therefore unclarifying the clinical significance ${ }^{38,39}$.

\section{Surgical treatment}

Making the decision of surgical treatment in $\mathrm{PHT}$ can be difficult. It seems that the basic pathology in PHT is tendinosis of the proximal hamstring tendons especially of the semimembranosus (SM). However, sciatic nerve's close relation to the proximal hamstring tendons has to be taken also into consideration ${ }^{4,11,12,46,47}$. Surgical and MRI findings have shown that adhesions between the sciatic nerve and proximal hamstring tendons may occasionally be present and also in some cases thickened and swollen proximal hamstring tendons can even cause direct compression to the sciatic nerve $4,11,46,48$. The sciatic nerve may be maximally tautened and impinged during the forward swing phase of running because of swollen tendons and ad- 
hesions ${ }^{46}$. This irritation of sciatic nerve may aggravate the pain caused by hamstring tendinosis alone ${ }^{4,11}$.

According to author's own experience chronic PHT can be quite resistant to conservative treatment. However, response for surgical treatment in PHT seems to be mainly good with low complication rate $4,11,12,46$. According to study by Lempainen et al., 80 of 90 patients were able to return to the same level of sporting activity as before the onset of the symptoms after surgery ${ }^{4}$. This took an average of five months (range, 2-12). Similar results have also been reported after surgery in non-athletic patients with chronic PHT symptoms ${ }^{12}$.

The surgical intervention is to some extent analogous to the partial adductor tenotomy done for tendinopathy, implicating a proposed stress shield theory including redistribution of tendon load or simply denervation of nosiseptic nerve-endings ${ }^{49,50}$.

\section{Surgical technique and rehabilitation}

In surgery, the patient is placed in a prone position. The ischial tuberosity is exposed either via a transverse gluteal crease incision or via a longitudinal posterior incision by retracting superiorly the inferior border of the gluteus maximus muscle. The proximal attachment sites of the hamstring muscles are identified and a transverse tenotomy is done to the thickened semimembranosus tendon 3-4 cm distal to its origin. The biceps femoris and semitendinosus muscles are normally left intact. A small cleavage is also done to lateral edge BF tendon if it looks swollen and edematous. The partially tenotomized semimembranosus tendon is then sutured securelily to the biceps femoris tendon to prevent excessive retraction. After tenotomy the sciatic nerve is explored and freed from adhesions if necessary. The procedure is presented in schematic drawings (Figs. 2-4) of the right proximal hamstring muscle insertion.

After surgery the patient is allowed to begin full weight bearing gradually during the first 2 postoperative weeks. All kind of stretching and pressure to the hamstrings are avoided first three to four weeks. Light swimming and aqua training are allowed 2-3 weeks after surgery. Bicycling with gradually increasing time and intensity is begun after 4 weeks. Running and heavier weight training are typically allowed 2 months after the operation.

\section{Conclusion}

According to our experience, treating PHT represents an exceptional challenge. Management is often casebased and athlete-specific with adequate balance of the multimodal traditional treatment methods, supported by novel approaches in recalcitrant diseases refractory to conventional treatment. Also motivation and compliance of the patient to daily self-therapy and adequate modification or pause of sporting activity is of great importance. In cases where patients show no

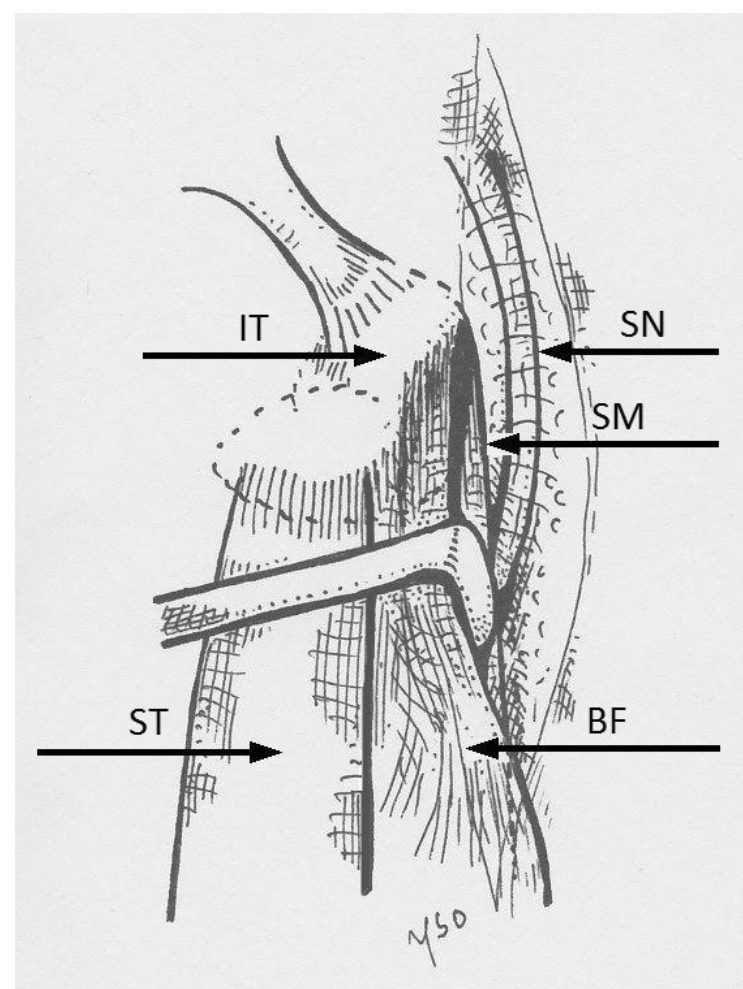

Figure 2. A schematic drawing of the right hamstring muscle anatomy. The semimembranosus tendon (SM) is related anteriorly to the biceps femoris muscle (BF). The sciatic nerve (SN) curves lateral side of the ischial tuberosity (IT). The semitendinosus muscle (ST) is medial to the BF. In this figure the lateral edge of the BF is pulled medially to expose the thickened and edematous SM tendon.

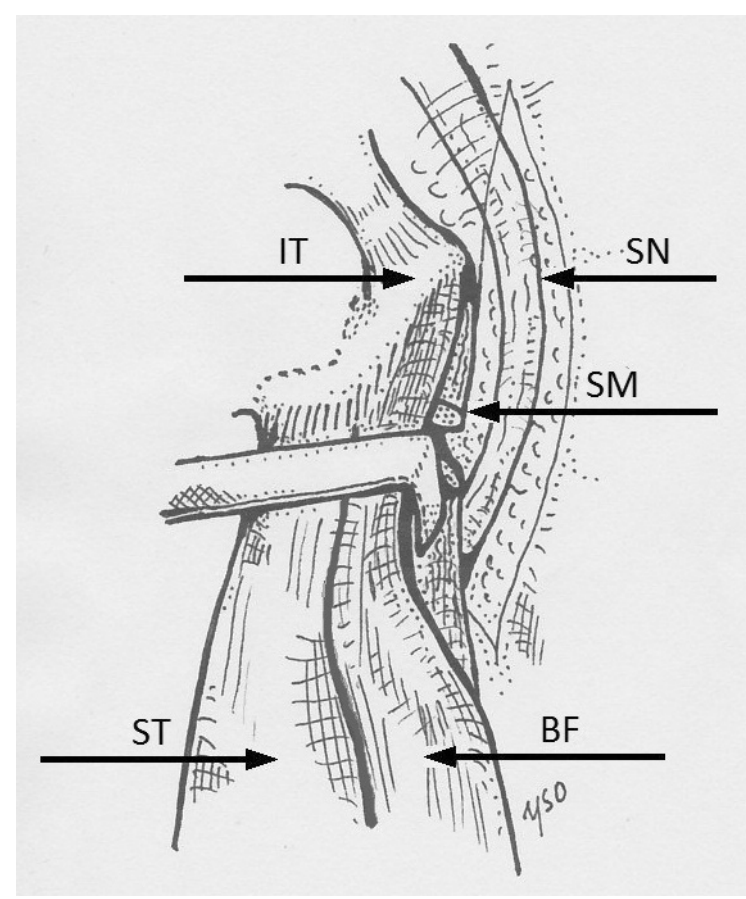

Figure 3. Tenotomy is performed to the lateral side of the SM tendon and the sciatic nerve gently explored. 


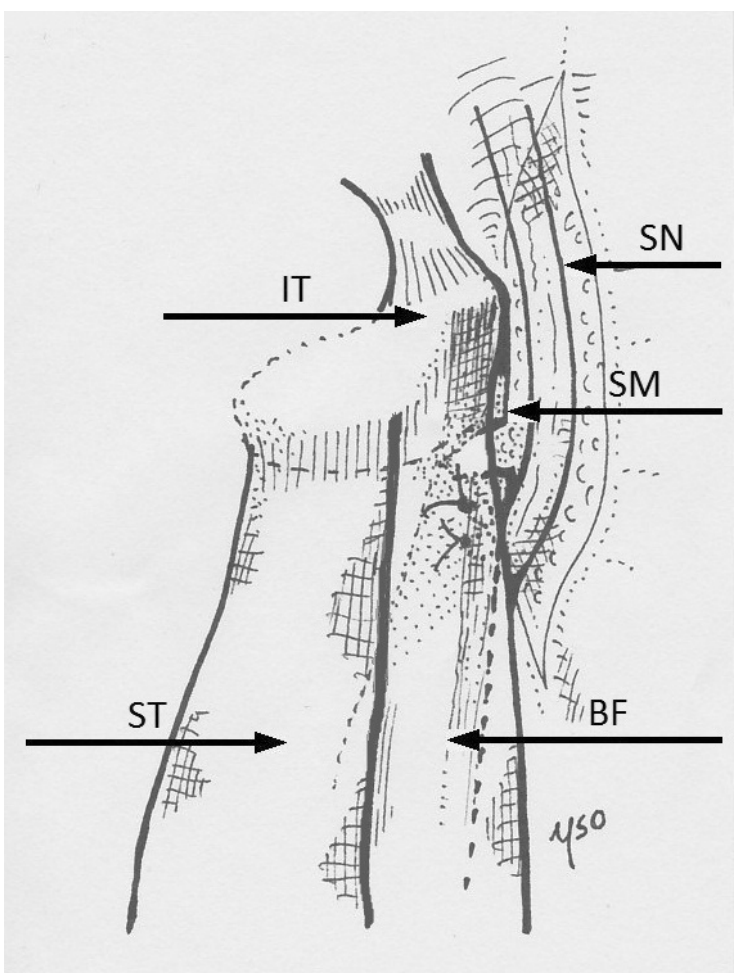

Figure 4. The distal head of the tenotomized SM tendon sutured to the BF tendon.

improvement despite good compliance to sufficient conservative treatment (usually 6 months in exertion injuries), surgical intervention can be considered due to successful reports of surgical treatment ${ }^{4,22}$. When choosing a suitable treatment method, it should also be remembered that PHT can be a career ending disorder for a top-level athlete. The etiology of PHT is still unclear, and it might be the same as in e.g. Achilles and patellar tendinopathy. Pathophysiological comparisons to other tendons should be made with caution due to different anatomy and strains. Uncertainty remains as to which external and internal attributes relate to tendinopathy.

Considering future research projects of PHT, a rating system including evaluation of histological degree of tendinosis combined with clinical and MRI findings should be developed, aiding clinical decision making. This would mean international clinical collaboration for attaining sufficiently powered studies.

\section{Disclosure}

The author reports no conflicts of interest in this work.

\section{References}

1. Lempainen L, Banke IJ, Johansson K, Brucker PU, Sarimo J, Orava S, et al. Clinical principles in the management of hamstring injuries. Knee Surg Sports Traumatol Arthrosc. 2014.
2. Maffulli N, Khan KM, Puddu G. Overuse tendon conditions: time to change a confusing terminology. Arthroscopy. 1998; 14(8):840-843.

3. Padulo J, Oliva F, Frizziero A, Maffulli N. Muscles, Ligaments and Tendons Journal. Basic principles and recommendations in clinical and field science research. MLTJ. 2013; 4:250-252.

4. Lempainen L, Sarimo J, Mattila K, Vaittinen S, Orava S. Proximal hamstring tendinopathy: results of surgical management and histopathologic findings. Am J Sports Med. 2009;37(4): 727-734.

5. Roels J, Martens M, Mulier JC, Burssens A. Patellar tendinitis (jumper's knee). Am J Sports Med. 1978;6(6):362-368.

6. Puddu G, Ippolito E, Postacchini F. A classification of Achilles tendon disease. Am J Sports Med. 1976;4(4):145-150.

7. Lui PPY, Maffulli N, Rolf C, Smith RKW. What are the validated animal models for tendinopathy? Scand J Med Sci Sports. 2011;21(1):3-17.

8. Millar NL, Murrell GAC. Heat shock proteins in tendinopathy: novel molecular regulators. Mediators Inflamm. 2012.

9. Rui YF, Lui PPY, Rolf CG, Wong YM, Lee YW, Chan KM. Expression of chondro-osteogenic BMPs in clinical samples of patellar tendinopathy. Knee Surg Sports Traumatol Arthrosc. 2012;20(7):1409-1417.

10. Abrahams $Y$, Laguette M-J, Prince S, Collins M. Polymorphisms within the COL5A1 3'-UTR that alters mRNA structure and the MIR608 gene are associated with Achilles tendinopathy. Ann Hum Genet. 2013;77(3):204-214.

11. Puranen J, Orava S. The hamstring syndrome. A new diagnosis of gluteal sciatic pain. Am J Sports Med. 1988;16(5):517521.

12. Saikku K, Vasenius J, Saar P. Entrapment of the proximal sciatic nerve by the hamstring tendons. Acta Orthop Belg. 2010;76(3):321-324.

13. Kannus $P$, Józsa L. Histopathological changes preceding spontaneous rupture of a tendon. A controlled study of $891 \mathrm{pa}-$ tients. J Bone Joint Surg Am. 1991;73(10):1507-1525.

14. Ruzzini L, Abbruzzese F, Rainer A, Longo UG, Trombetta M, Maffulli N, et al. Characterization of age-related changes of tendon stem cells from adult human tendons. Knee Surg Sports Traumatol Arthrosc. 2013.

15. Khan KM, Cook JL, Bonar F, Harcourt P, Astrom M. Histopathology of common tendinopathies. Update and implications for clinical management. Sports Med. 1999;27(6):393-408.

16. Kannus P. Etiology and pathophysiology of chronic tendon disorders in sports. Scand J Med Sci Sports. 1997;7(2):78-85.

17. Van der Worp $H$, van Ark M, Roerink S, Pepping G-J, van den Akker-Scheek I, Zwerver J. Risk factors for patellar tendinopathy: a systematic review of the literature. $\mathrm{Br} \mathrm{J}$ Sports Med. 2011;45(5):446-452.

18. Orava S, Leppilahti J, Karpakka J. Operative treatment of typical overuse injuries in sport. Ann Chir Gynaecol. 1991; 80(2):208-211.

19. Cacchio A, Rompe JD, Furia JP, Susi P, Santilli V, De Paulis F. Shockwave therapy for the treatment of chronic proximal hamstring tendinopathy in professional athletes. Am J Sports Med. 2011;39(1):146-153.

20. Cacchio A, Borra F, Severini G, Foglia A, Musarra F, Taddio N, et al. Reliability and validity of three pain provocation tests used for the diagnosis of chronic proximal hamstring tendinopathy. Br J Sports Med. 2012;46(12):883-887.

21. Cacchio A, De Paulis F, Maffulli N. Development and validation of a new visa questionnaire (VISA-H) for patients with proximal hamstring tendinopathy. Br J Sports Med. 2014;48(6):448-452.

22. Benazzo F, Marullo M, Zanon G, Indino C, Pelillo F. Surgical management of chronic proximal hamstring tendinopathy in athletes: a 2 to 11 years of follow-up. J Orthop Traumatol. 2013;14(2):83-89. 
23. Zissen MH, Wallace G, Stevens KJ, Fredericson M, Beaulieu CF. High hamstring tendinopathy: MRI and ultrasound imaging and therapeutic efficacy of percutaneous corticosteroid injection. AJR Am J Roentgenol. 2010;195(4):993-998.

24. White KE. High hamstring tendinopathy in 3 female long distance runners. J Chiropr Med. 2011;10(2):93-99.

25. Fredericson M, Moore W, Guillet M, Beaulieu C. High hamstring tendinopathy in runners: meeting the challenges of diagnosis, treatment, and rehabilitation. Phys Sportsmed. 2005; 33(5):32-43.

26. Linklater JM, Hamilton B, Carmichael J, Orchard J, Wood DG Hamstring injuries: anatomy, imaging, and intervention. Semin Musculoskelet Radiol. 2010;14(2):131-161.

27. Koulouris G, Connell D. Hamstring muscle complex: an imaging review. Radiographics. 2005;25(3):571-586.

28. De Smet AA, Blankenbaker DG, Alsheik NH, Lindstrom MJ. $\mathrm{MRI}$ appearance of the proximal hamstring tendons in patients with and without symptomatic proximal hamstring tendinopathy. AJR Am J Roentgenol. 2012;198(2):418-422.

29. Mendiguchia J, Alentorn-Geli E, Brughelli M. Hamstring strain injuries: are we heading in the right direction? Br J Sports Med. 2012;46(2):81-85.

30. Lempainen L, Sarimo J, Mattila K, Orava S. Proximal Hamstring Tendinopathy-Overview of the Problem With Emphasis on the Surgical Treatment. Oper Tech Sports Med. 2009;17(4):225-228.

31. Lorenz D, Reiman M. The role and implementation of eccentric training in athletic rehabilitation: tendinopathy, hamstring strains, and acl reconstruction. Int J Sports Phys Ther. 2011; 6(1):27-44

32. Kujala UM, Orava S, Järvinen M. Hamstring injuries. Current trends in treatment and prevention. Sports Med. 1997;23(6): 397-404.

33. McCormack JR. The management of bilateral high hamstring tendinopathy with $A S T Y M{ }^{\circledR}$ treatment and eccentric exercise: a case report. J Man Manip Ther. 2012;20(3):142-146.

34. Jayaseelan DJ, Moats N, Ricardo CR. Rehabilitation of Proximal Hamstring Tendinopathy Utilizing Eccentric Training, Lumbopelvic Stabilization, and Trigger Point Dry Needling: 2 Case Reports. J Orthop Sports Phys Ther. 2013;44(3):198205.

35. Zhang J, Wang JH-C. Mechanobiological response of tendon stem cells: implications of tendon homeostasis and pathogenesis of tendinopathy. J Orthop Res. 2010;28(5):639-643.

36. Khan $\mathrm{K}$, Cook J. The painful nonruptured tendon: clinical aspects. Clin Sports Med. 2003;22(4):711-725.
37. Wilson JJ, Best TM. Common overuse tendon problems: A review and recommendations for treatment. Am Fam Physician. 2005;72(5):811-818.

38. Wetzel RJ, Patel RM, Terry MA. Platelet-rich plasma as an effective treatment for proximal hamstring injuries. Orthopedics. 2013;36(1):e64-70.

39. Mautner K, Colberg RE, Malanga G, Borg-Stein JP, Harmon KG, Dharamsi AS, et al. Outcomes after ultrasound-guided platelet-rich plasma injections for chronic tendinopathy: a multicenter, retrospective review. PM R. 2013;5(3):169-175.

40. Drezner JA. Practical management: hamstring muscle injuries. Clin J Sport Med. 2003;13(1):48-52.

41. Levine WN, Bergfeld JA, Tessendorf W, Moorman CT. Intramuscular corticosteroid injection for hamstring injuries. A 13year experience in the National Football League. Am J Sports Med. 2000;28(3):297-300.

42. Kennedy JC, Willis RB. The effects of local steroid injections on tendons: a biomechanical and microscopic correlative study. Am J Sports Med. 1978;4(1):11-21.

43. Nicholson LT, DiSegna S, Newman JS, Miller SL. Fluoroscopically Guided Peritendinous Corticosteroid Injection for Proximal Hamstring Tendinopathy: A Retrospective Review. Orthop J Sport Med. 2014;2(3).

44. Baksh N, Hannon CP, Murawski CD, Smyth NA, Kennedy JG. Platelet-rich plasma in tendon models: a systematic review of basic science literature. Arthroscopy. 2013;29(3):596-607.

45. Engebretsen L, Steffen K, Alsousou J, Anitua E, Bachl N, Devilee $\mathrm{R}$, et al. IOC consensus paper on the use of platelet-rich plasma in sports medicine. Br J Sports Med. 2010;44(15):10721081.

46. Migliorini S, Merlo M. The hamstring syndrome in endurance athletes. Br J Sports Med. 2011;45(4):363-363.

47. Miller SL, Gill J, Webb GR. The proximal origin of the hamstrings and surrounding anatomy encountered during repair. A cadaveric study. J Bone Joint Surg Am. The Journal of Bone and Joint Surgery. 2007;89(1):44-48.

48. De Paulis F, Cacchio A, Michelini O, Damiani A, Saggini R. Sports injuries in the pelvis and hip: diagnostic imaging. Eur $\mathrm{J}$ Radiol. 1998;27 Suppl 1:S49-59.

49. Van Sterkenburg MN, van Dijk CN. Mid-portion Achilles tendinopathy: why painful? An evidence-based philosophy. Knee Surg Sports Traumatol Arthrosc. 2011;19(8):1367-1375.

50. Orchard JW, Cook JL, Halpin N. Stress-shielding as a cause of insertional tendinopathy: the operative technique of limited adductor tenotomy supports this theory. J Sci Med Sport. 2004;7(4):424-428. 